\title{
Relationship between Religiosity and Life Satisfaction in Undergraduate Students at Kohat University of Science \& Technology KPK Pakistan
}

\author{
Nayab Zahoor ${ }^{1}$, Alam Zeb Khattak ${ }^{2}$, Muhammad Amjad $^{3}$, Sukaina Shaukat ${ }^{1}$, Uzma Khanum ${ }^{1}$, \\ Urooj Raziq ${ }^{1}$
}

\section{Abstract}

The present study was conducted to investigate the relationship between closeness to religion and satisfaction in life in undergraduate students at Kohat University of Science \& Technology (KUST), KPK, Pakistan. A total sample of 100 undergraduate students was selected through a convenience sampling technique comprising 50 male and 50 female undergraduate students. The questionnaires were uploaded as Google forms to collect data virtually from the participants due to the current COVID-19 pandemic in Pakistan. The undergraduate students having age range 2022 years were included in the study. Two different standardized tools, Satisfaction with Life Scale developed by Diener et al. (1985) and Daily Spiritual Experience Scale developed by Underwood and Teresi (2002) were used. The data was analyzed by mean, standard deviation, and Pearson's product-moment correlation. The results showed significant positive correlations between religiosity, religious well-being, and life satisfaction. It is suggested for researchers to explore more variables related to religiosity and life satisfaction.

Keywords: Attachment to GOD; Happiness; Religiosity; Satisfaction in life; Subjective wellbeing

Received: 16 March 2021; Revised Received: 06 July 2021; Accepted: 13 July 2021

${ }^{1}$ Research Scholar, Dept of Education \& Psychology, Kohat University of Science \& Technology, Kohat, KPK, Pakistan.

${ }^{2} \mathrm{PhD}$ Scholar, Dept of Psychology, International Islamic University, Islamabad, Pakistan.

${ }^{3}$ Lecturer, Dept of Education \& Psychology, Kohat University of Science \& Technology, Kohat, KPK, Pakistan.

\section{Corresponding Author Email:}

masoomalam2016@gmail.com

\section{Introduction}

Religiosity is the influential factor of an individual's well-being over the life span. It has a direct effect on someone's well-being. Religiosity and religious beliefs are related to certain important features, including wellbeing, life satisfaction, and happiness in life. Our health and social settings are also under the influence of religiosity. In the current study, an effort has been made to explore the relationship between religiosity and life satisfaction. Religiosity has been defined as the attachment with religion and religious beliefs associated with various dimensions. In other words, it is a state of mind where an individual feel satisfied. Previous research studies reported that religiosity as a unidimensional perception. It focuses on religious turnout. Religion is a complete system of beliefs and principles in heavenly or superhuman supremacy, codes, and principles of worship. These are related to other routines directed towards such a power (Beit-Hallahmi \& Argyle, 1975). Some of the recent studies stated the significance of assessing religiosity as a multi-factorial conception that focuses on all domains including behavioral, subjective, cognitive, social, and cultural components. This multidimensionality made it a complex phenomenon.

This article is distributed under the terms of the Creative Commons Attribution Non Commercial 4.0 License (http://www.creativecommons.org/licenses/by-nc/4.0/) which permits nonCommercial use, reproduction and distribution of the work without further permission provided the original work is attributed as specified. 
Different features of religiosity including private devotion and existential inevitability are similarly viewed as essential constituents of the related attribute. Religiosity is known as the sub-dimension of the culture viewed in more obvious as well as a stable phenomenon through extensive periods (McDaniel \& Burnett, 1990). We can define spirituality as "the presence of a relationship with a higher Power that affects how one operates in the world" (Armstrong, 1995). The theoretical explanations of religiosity are the connection among those that are beyond biological, mental or societal human observation or practice. This relationship of spirituality can be termed as "divinity", "a higher power", a "divine being", "ultimate reality", "God" or "god-being" (Dyson et al., 1997). Therefore, spirituality is another supplementary inner characteristic that is linked with satisfaction in human life. Some empirical research studies supported the notion of religious and spiritual importance in our day-to-day life. Most of the studies on spirituality and devoutness described modest positive relationships between inner characteristics and subjective wellbeing together with life satisfaction (Zullig et al., 2006). Some of the research studies reported a strong relationship between spirituality and other related outcomes including physical and mental health. Happiness, well-being and life satisfaction are the important variables of the current era studied in positive psychology, economics, and other social sciences. Social scientists are more interested to explore the phenomena leading to more happiness and satisfaction (Conzo et al., 2017). Life satisfaction is considered an intellectual component related to subjective well-being. These variables are preferred and measured in the scrutiny of pleasure in social disciplines (Diener \& Emmons, 1984).

Some cross-cultural researches demonstrated the lower levels of life satisfaction in Korean adolescents than their American counterparts
(Park \& Huebner, 2005). Similarly, an international study conducted with college students found that individuals from the collectivistic type of societies like Korean civilizations reported minor levels of life satisfaction compared to those living in individualistic societies like United States (Diener \& Diener, 1995).

These differences appear to be attributed to differences in cultural values. Diener and Diener (1995) reported merely high individualism which predicted life satisfaction when other variables were controlled. Additionally, Park and Huebner (2005) showed that the discrepancy in levels of life satisfaction was highest in the selfdomain; as members of an individualistic society. Life satisfaction is relatively the measure of excellence in someone's life. So, the assessment of this relative measure delivers the intellectual aspect of cheerfulness and pleasure, which is different from the other two constituents of subjective well-being which are pleasurable and unpleasant effects. Religiosity is extensively studied in social sciences due to its positive relation to well-being, happiness, and overall life satisfaction (Mochon et al., 2011; Yeniaras \& Akarsu, 2017). Consequently, research studies reported that empathy, kindness, prosocial behavior, and unselfishness is rooted in all religions. These are the important factors of life satisfaction. Given the benefits of bolstering life satisfaction, it is important to recognize what factors may donate to life satisfaction in young people.

There are growing indications suggesting that religiosity, as well as spirituality, promote mental and psychological wellbeing in adolescents. However, there is a lack of consensus regarding what constitutes religiosity and spirituality, with some conceptualizing the two terms as related rather than independent constructs (Hill \& Pargament, 2003). The combined term, 
religiosity/spirituality $(\mathrm{R} / \mathrm{S})$ is used in the present study, and the joint construct is defined in terms of one of the measures employed in the study. Different research studies hypothesized "attachment to God" as a belief that God is involved vigorously in an individual's life and is available to provide supervision and maintenance (Kirkpatrick 1992, 2005). Human connection with God is essential to numerous theistic beliefs and it boosts the development of belief associated opposite to the spirit of uncertainty and apprehension (Kirkpatrick 1992, 2005). For cheerfulness, comfort, life satisfaction, and well-being of religious individuals, secure attachment with God is essential. (Belavich \& Pargament 2002). A mechanism whereby attachment to God protects wellbeing is the level of intimacy, in which an individual feels immortal, but it is dissimilar in important ways. Like attachment to God does not necessarily capture internal working models which help to explain, why God is regarded as a safe, secure, and protected base.

Instead, it demands the degree of mutuality, provision, support, attention, and

\section{Objective \& Hypothesis of the Study}

The objective of the study was to evaluate the relationship between religiosity and satisfaction in life in undergraduate students at KUST, KPK, Pakistan. It was

\section{Method}

\section{Participants}

This cross-sectional, correlative study was conducted in a public sector university, KUST. All the undergraduate students of faculties of social sciences, physical sciences, and biological sciences constituted the population of the study. The three faculties had 16 departments with a total of 1856 undergraduate students enrolled during the Fall 2017 to Spring 2020. A total sample of 100 undergraduate students from these 16 departments of KUST was selected through understanding between someone and God (Hill \& Pargament, 2003; Manglos-Weber et al, 2016; Proeschold-Bell, 2014). Additionally, research studies found that a secure attachment to Divinity impacts internal working models in ways similar to what attachment studies have found (Kirkpatrick 2005; Rowatt \& Kirkpatrick 2002). The concept of religiosity comprises of someone's anticipation related to the optimistic collective functions in their life aided by related pious societies. This is also related to the presence of various spiritual powers that influence the world. Some earlier researches revealed no substantial relationship between religiosity and satisfaction in life (Beck, 2006).

A significant body of research indicates that in adults, a high level of life satisfaction serves as a protective factor, contributing to improved physiological and emotional vigor, social, rational, and personal relationships. Technical skills and different occupational consequences are also aided (Diener et al., 2002).

hypothesized that there is a positive relationship between religiosity and satisfaction in life in undergraduate students at KUST, KPK, Pakistan.

the convivence sampling technique including 50 male and 50 female undergraduate students.

\section{Instruments}

\section{Satisfaction with Life Scale (SWLS)}

This scale was developed by Diener et al in 1985. This scale consists of 5 items with 7 points Likert scale from strongly disagree $=1$ to strongly agree $=7$. The minimum score on this scale is 5 and the maximum score is 35 (Diener et al., 1985). 


\section{Daily Spiritual Experience Scale (DSES)} This scale was originally developed by Underwood and Teresi (2002). A 16- item self-report measure of spiritual experience. The first 15 items have a uniform scoring method with 6 points Likert scale from almost never $=1$ to many times a day $=6$. The score on item 16 is recorded on 4 points Likert scale from not close at all $=1$ to as close as possible $=4$.

Procedure

For the present research, the sample was approached in Kohat University of Science \&
Technology, KPK, Pakistan. Informed consent was taken from participants to know their readiness and inclination to take part in the research. They were asked to read the instruction carefully. They were also directed to record their responses on every item. They were assured of their rights of anonymity, confidentiality, and right to quit any time without giving any reason to the researcher. They were also assured that the data will only be used for research purposes. The research is based on online forms to collect data from participants through the survey method.

\section{Results}

Table 1

Pearson's Correlation between Religiosity and Life Satisfaction in Undergraduate Students $(N=100)$

\begin{tabular}{lcccc}
\hline Variables & M & SD & $\mathbf{1}$ & $\mathbf{2}$ \\
\hline Religiosity & 5.23 & 1.23 & - & - \\
Life Satisfaction & 2.52 & 0.78 & $0.72^{* *}$ & -
\end{tabular}

$* * P<0.01$

As described in table 1, a bivariate Pearson's product-moment correlation was run to find out the relationship between religiosity and life satisfaction in undergraduate students. The value of correlations coefficient $(r)$ was found to be 0.72 which indicates a strong

\section{Discussion}

Most of the previous researches showed a positive correlation between a good religious attitude and satisfaction in life. Individuals involved in religious practices show more qualities that are responsible for life satisfaction i.e. optimism, gratitude, and healthy relationships. The result of our study is parallel to many other previous researches. Our findings showed positive direct impact on life satisfaction from all dimensions of religiosity, suggesting that religious devotion is useful and beneficial to all people irrespective of whether they are focused intrinsically, fundamentally, or extrinsically (societal or private). Spirituality is an extra significant $(\mathrm{p}<0.01)$ positive relationship between religiosity and life satisfaction. It shows that higher the religiosity of undergraduate students, higher will be their life satisfaction and vice versa.

internal function that has been related to the happiness of life. In the last few years, observational studies have supported the importance of spirituality in daily life. In general, spirituality and religious studies have shown moderate positive associations between inner features and subjective wellbeing as well as life satisfaction. An increasing body of investigation through research indicates that spirituality is correlated with different outcomes, including physical health, mental health, and psychological well-being. Culver and Denton (2017) examined whether attachment to God measured at an earlier wave of data associates 
with life purpose at a later wave. Positive long-term associations between closeness to God and life purpose were reported. Proeschold-Bell et al. (2014) correlates longitudinal studies related to psychological issues like depression, anxiety, stress, emotional exhaustion, and depersonalization. Negative correlations between closeness to God and each outcome were found at twotime points, two years apart. Studies found that religious individuals hold powerful and richly imaginative concepts of God as an always available partner (Beck, 2006; Hill \& Pargament, 2003; Kirkpatrick, 1992; Laurin et al., 2014; Luhrmann, 2012; ManglosWeber et al., 2016; Unnever et al., 2006). Attachment to God also predicts high levels of life satisfaction, self-esteem, and optimism (Bradshaw \& Kent, 2018; Kent et al., 2018). Although researchers have not concluded an agreement on which aspects of religiosity affect life satisfaction the most. Krause (1993) reported numerous probable explanations for the positive relationship between religiosity and life satisfaction. Social support, coordination, and collaboration may have benefits like improved religious affiliation which in turn

\section{Conflict of Interest}

There is no conflict of interest among authors.

\section{References}

Armstrong, D. (1995). The rise of surveillance medicine. Sociology of health \& illness, 17(3), 393-404.

Beck, R. (2006). God as a Secure Base: Attachment to God and Theological Exploration. Journal of Psychology and Theology, 34(2), 125-132.

Beit-Hallahmi, B., \& Argyle, M. (1975). God as a father-projection: The theory and the evidence. British Journal of Medical Psychology, 48(1), 71-75. also increases overall life satisfaction. Researchers have also suggested that improved religious affiliation may change almost all lifestyle varieties and choices which are healthier and produce optimistic consequences and hereafter it also increases satisfaction with life. Individual private religious commitment and attachment may be directed to life satisfaction more subjectively. Establishing a heavenly religious relationship provide consolation, maintenance, and meaning to life (Schwab \& Peterson, 1990).

\section{Limitations \& Suggestions}

There might be other important factors that were not measured in this study. Age group limitation, only 20-40 years individuals were selected for evaluations which should broaden to have a better understanding of all age group satisfaction levels toward religion. Moreover, our research covers the general view of religiosity and life satisfaction irrespective of gender differences. It is suggested for researchers to conduct the study to evaluate the effect of gender differences on religiosity.

\section{Source of Funding}

The authors declared no source of funding.

Belavich, T. G., \& Pargament, K. I. (2002). The Role of Attachment in Predicting Spiritual Coping with a Loved One in Surgery. Journal of Adult Development, 9(1), 13-29.

Bradshaw, M., \& Kent, B. V. (2018). Prayer, Attachment to God, and Changes in Psychological Well-Being in Later Life. Journal of aging and health, 30(5), 667-691. https://doi.org/10.1177/08982643166 88116 
Conzo, P., Aassve, A., Fuochi, G., \& Mencarini, L. (2017). The cultural foundations of happiness. Journal of Economic Psychology, 62, 268-283. https://doi.org/10.1016/j.joep.2017.0 8.001

Culver, J., \& Denton, M. L. (2017). Religious Attachment and the Sense of Life Purpose among Emerging Adults. Religions, $\quad 8(12), \quad 274$. https://doi.org/10.3390/rel812027 4

Diener, E., \& Diener, M. (1995). Crosscultural correlates of life satisfaction and self-esteem. Journal of Personality and Social Psychology, 68(4), $653-$ 663. https://doi.org/10.1037/00223514.68.4.653

Diener, E., Emmons, R. A., Larsen, R. J., \& Griffin, S. (1985). The Satisfaction with Life Scale. Journal of Personality Assessment, 49, 71-75.

Diener, E., \& Emmons, R. A. (1984). The independence of positive and negative affect. Journal of personality and social psychology, 47(5), 1105.

Diener, E., Lucas, R. E., Oishi, S. (2002). Subjective wellbeing: The science of happiness and life satisfaction. https://doi.org/10.1093/oxfordhb/978 0195187243.013 .0017

Dyson, J., Cobb, M., \& Forman, D. (1997). The meaning of spirituality: A literature review. Journal of advanced nursing, 26(6), 1183-1188.

Hill, P. C., \& Pargament, K. I. (2003). Advances in the Conceptualization and Measurement of Religion and Spirituality: Implications for Physical and Mental Health Research. American Psychologist, 58(1), 64-74.

Kent, B. V., Bradshaw, M., \& Uecker, J. E. (2018). Forgiveness, attachment to God, and mental health outcomes in older US adults: A longitudinal study. Research on Aging, 40, 456-479.

Kirkpatrick, L. A. (1992). An Attachmenttheory Approach to the Psychology of Religion. The International Journal for the Psychology, 2(1), 3-28.

Kirkpatrick, L. A. (2005). Attachment, Evolution, and the Psychology of Religion. Guilford Press.

Krause, N. (1993). Measuring religiosity in later life. Research on Aging, 15(2), 170 -

197. https://doi.org/10.1177/0164027 593152003

Laurin, K., Schumann, K., \& Holmes, J. G. (2014). A Relationship with God? Connecting with the Divine to Assuage Fears of Interpersonal Rejection. Social Psychological and Personality Science, 5(7), 777-785.

Luhrmann, T. M. (2012). When God Talks Back: Understanding the American Evangelical Relationship with God. Vintage.

McDaniel, S.W. \& Burnett, J. J. (1990). Consumer religiosity and retail store evaluative criteria. Journal of the Academy of marketing Science, 18(2), 101-112.

Manglos-Weber, N. D., Mooney, M. A., Bollen, K. A., \& Roos, J. M. (2016). Relationships with God among Young Adults: Validating a Measurement Model with Four Dimensions. Sociology of Religion, 77(2), 193-213.

Park, N., \& Huebner, E. S. (2005). A crosscultural study of the levels and correlates of life satisfaction among adolescents. Journal of CrossCultural Psychology, 36(4), 444-456.

Proeschold-Bell, R. J., Yang, C., Toth, M., Rivers, M. C., \& Carder, K. (2014). Closeness to God among Those Doing God's Work: A Spiritual 
WellBeing Measure for Clergy. Journal of Religion and Health, 53(3), 878-894.

Rowatt, W., \& Kirkpatrick, L. A. (2002). Two Dimensions of Attachment to God and their Relation to Affect, Religiosity, and Personality Constructs. Journal for the Scientific Study of Religion, 41(4), 637-651.

Schwab, R., \& Petersen, K. U. (1990). Religiousness: Its relation to loneliness, neuroticism and subjective well-being. Journal for the Scientific Study of Religion, 29(3), 335-

345. https://doi.org/10.2307/1386462

Underwood, L. G., \& Teresi, J. (2002). The Daily Spiritual Experience Scale: Development, theoretical description, reliability, exploratory factor analysis, and preliminary construct validity using health related data. Annals of Behavioral Medicine, 24, 22-33.

Unnever, J. D., Cullen, F. T., \& Bartowski, J. P. (2006). Images of God and Public Support for Capital Punishment: Does a Close Relationship with a Loving God Matter? Criminology, 44(4), 835866.

Yeniaras, V., \& Akarsu, T. N. (2017). Religiosity and life satisfaction: A multi-dimensional approach. Journal of Happiness Studies: An Interdisciplinary Forum on Subjective Well-Being, 18(6), 18151840. https://doi.org/10.1007/s10902 $-016-9803-4$

Zullig, K. J., Ward, R. M., \& Horn, T. (2006). The association between perceived spirituality, religiosity, and life satisfaction: The mediating role of self-rated health. Social Indicators Research, 79, 255- 274. 